HB31

M415

no. $06-22$

2006 
Digitized by the Internet Archive in 2011 with funding from Boston Library Consortium Member Libraries 


Massachusetts Institute of Technology

Department of Economics

Working Paper Series

\title{
A NEW KEYNESIAN MODEL WITH UNEMPLOYMENT
}

\author{
Olivier Blanchard \\ Jordi Gali
}

\author{
Working Paper 06-22 \\ July 18, 2006 \\ Room E52-251 \\ 50 Memorial Drive \\ Cambridge, MA 02142
}




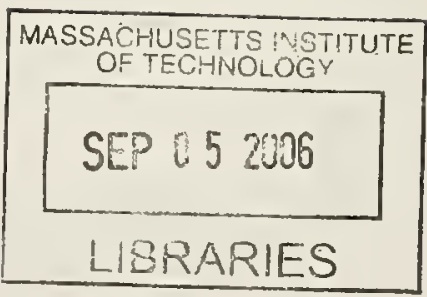




\title{
A New Keynesian Model with Unemployment*
}

\author{
Olivier Blanchard ${ }^{\dagger} \quad$ Jordi Galí ${ }^{\ddagger}$
}

July 18, 2006 (first draft: March 2006)

\begin{abstract}
We develop a utility based model of fluctuations, with nominal rigidities, and unemployment. In doing so, we combine two strands of research: the New Keynesian model with its focus on nominal rigidities, and the Diamond-MortensenPissarides model, with its focus on labor market frictions and unemployment. In developing this model, we proceed in two steps.

We first leave nominal rigidities aside. We show that, under a standard utility specification, productivity shocks have no effect on unemployment in the constrained efficient allocation. We then focus on the implications of alternative real wage setting mechanisms for fluctuations in unemployment.

We then introduce nominal rigidities in the form of staggered price setting by firms. We derive the relation between inflation and unemployment and discuss how it is influenced by the presence of real wage rigidities. We show the nature of the tradeoff between inflation and unemployment stabilization, and we draw the implications for optimal monetary policy.
\end{abstract}

JEL Classification: E32, E50. Keywords: new Keynesian model, labor market frictions, search model, unemployment, sticky prices, real wage rigidities.

* We thank Ricardo Caballero, Peter Ireland, Julio Rotemberg, and participants in seminars at ITAM, MIT, Wharton, Boston Fed, and at the UQAM conference on "Frontiers of Macroeconomics" for helpful comments. We also thank Dan Cao for valuable research assistance. $\dagger$ MIT and NBER

$\ddagger$ CREI, UPF, CEPR and NBER 
.

- - 


\section{Introduction}

Two different paradigms have come to dominate macroeconomics research over the past decade.

On the one hand, the New Keynesian model (the NK model, for short) has emerged as a powerful tool for monetary policy analysis in the presence of nominal rigidities. Its adoption as the backbone of the medium-scale models currently developed by many central banks and policy institutions is a clear reflection of its success. That success may be viewed as somewhat surprising given that the existing versions of the NK paradigm typically do not generate movements in unemployment, only voluntary movements in hours of work or employment. ${ }^{1}$

On the other hand, and independently, the Diamond-Mortensen-Pissarides model of search and matching (the DMP model, henceforth) has become a popular framework for the analysis of labor market frictions, labor market dynamics, and the implications of alternative policy interventions on unemployment. ${ }^{2}$ However, its assumption of linear utility and its abstraction from nominal rigidities (or from. the existence of money, for that matter), has limited its usefulness for monetary economists.

Our purpose in this paper is to provide a simple integration of these two strands of research. We do so not for the sake of integration, but because we believe a framework that combines the two is needed in order to accommodate simultaneously the following properties, which we hold to be relevant in industrialized economies:

- Variations in unemployment are an important aspect of fluctuations, both from a positive and a normative point of view.

- Labor market frictions and the nature of wage bargaining are central to understanding movements in unemployment.

- The effects of technology and other real shocks are largely determined by the nature of nominal rigidities and monetary policy, thus calling for an

1. Paradoxically, this was viewed as one of the main weaknesses of the RBC model (for example, Summers (1991)), but was then exported to the NK model.

2. See Pissarides (2000) for a description of the DMP model. 
analysis of the consequences of alternative monetary policy rules for the nature of fluctuations and the level of welfare.

In our model, frictions in labor markets are introduced by assuming the presence of hiring costs, which increase with the degree of labor market tightness. We start by showing that, under our assumptions on preferences and technology, the constrained-efficient allocation implies a constant level of unemployment.

Hiring costs, together with the fact that it takes time for unemployed workers to find'a job, lead to a surplus associated with existing employment relationships, with the wage determining how that surplus is split between firms and workers. We examine the consequences of two alternative wage setting structures for equilibrium. Under Nash-bargaining we recover the property of a constant unemployment rate which characterizes the constrained efficient allocation, though in the decentralized economy the implied level of unemployment is generally inefficient. That result of constant equilibrium unemployment, which stands in - contrast to Pissarides (2000) and Shimer (2005), among others, comes from the fact that, under our utility specification, the reservation wage, rather than being constant, increases in proportion to consumption and thus with productivity. The proportional increase in real wages and productivity leaves all labor market flows unaffected.

The above finding leads us to consider the scope for and the implications of real wage rigidity. As in Hall (2005), real wage rigidity affects hiring decisions, but not employment in existing matches. We characterize the dynamic effects of technology shocks on unemployment as a function of the degree of real wage rigidity and other characteristics of the labor market. In particular, we show that the size of unemployment fluctuations increases with the extent of real rigidities, whereas the persistence of those fluctuations is higher in economies with more sclerotic labor markets, i.e. markets with lower average job-finding and separation rates.

Independently of their size and persistence, fluctuations of unemployment are always inefficient in our model. When we introduce nominal rigidities, monetary policy can influence those fluctuations, motivating the analysis of the consequences of alternative monetary policies. We first consider two extreme policies. 
We show that fully stabilizing inflation leads to persistent movements in unemployment in response to productivity shocks. As productivity shocks would not affect unemployment in the constrained efficient allocation, this implies that these movements in unemployment, and by implication, strict inflation targeting, are suboptimal. The degree of persistence of unemployment depends on the underlying parameters of the economy. Interestingly, in light of the difference between the US and European labor markets, the more sclerotic the labor market, the more persistent are unemployment movements.

We then show that stabilizing unemployment can be achieved, but only at the cost of variable inflation, with inflation increasing for some time in response to an adverse technology shock.

We finally derive the optimal monetary policy. The latter implies stabilizing a weighted average of the variances of inflation and of unemployment. It implies therefore that an adverse productivity shocks lead to an increase in inflation and an increase in unemployment for some time. Interestingly, while the implied responses of inflation are similar under the U.S. and European calibrations, the required fluctuations in unemployment are larger under the U.S. calibration. We show how such optimal responses can be approximated reasonably well with a simple Taylor-type rule which has the central bank adjust the short-term nominal rate in response to variations in inflation and unemployment, with suitably chosen response coefficients.

We are not the first to point to the need for and attempt such an integration, with relevant papers ranging from Merz (1995) to Christoffel and Linzert (2005). We defer a presentation of the literature and of our relation to it to later in the paper. Put simply, we see our contribution as the development of a simple, analytically tractable model, which can be used to characterize the effects of different shocks, their relation to the underlying parameters of the economy, and to characterize optimal monetary policy. Such a framework seems potentially useful in guiding the development of larger and more realistic models.

The paper is organized as follows.

Section 2 sets up the basic model, leaving out nominal rigidities. We capture 
labor market frictions through external hiring costs. The latter are a function of labor market tightness, defined as the ratio of hires to the unemployment pool. We then characterize the constrained-efficient allocation, and show that productivity shocks have no effect on unemployment. The source of this neutrality is that income effects lead to changes in the wage proportional to changes in productivity-as would be the case in an economy without labor market frictions.

Section 3 characterizes the decentralized equilibrium under alternative wagesetting mechanisms. We first assume Nash bargained wages and derive the conditions under which the economy replicates the constrained efficient allocation. We then show that, under Nash bargaining, the neutrality property continues to hold. We then introduce real wage rigidities, and characterize the dynamic effects of productivity shocks on unemployment.

Section 4 introduces nominal rigidities, in the form of staggering of price decisions by firms. We show how the model reduces, to a close approximation, to simple relations between inflation, marginal cost, and unemployment. We derive the relation between inflation and unemployment implied by the model, and contrast it to the standard NK formulation. Put crudely, the model implies a significant effect of both the level and the change in unemployment on inflation, given expected inflation.

Section 5 then turns to the implications of our framework for monetary policy. It shows how stabilizing inflation in response to productivity shocks leads to large and inefficient (given that constrained-efficient unemployment is constant) movements in unemployment. It shows how the persistence of unemployment is higher in more sclerotic markets, markets in which the separation and the hiring rate are lower. It derives optimal monetary policy, and the implied movements in inflation and unemployment.

Section 6 offers two calibrations of the model, one aimed at capturing the United States, the other aimed at capturing Europe, with its more sclerotic labor markets. In each case, it presents the implications of pursuing either inflation-stabilizing, unemployment-stabilizing, or optimal monetary policy.

Section 7 indicates how our model relates to the existing-and rapidly growing- 
literature on the relative roles of labor market frictions, real wage rigidities, and nominal price rigidities in shaping fluctuations.

Section 8 concludes.

\section{A Simple Framework}

\subsection{Assumptions}

\section{Preferences}

The representative household is made up of a continuum of members represented by the unit interval. The household seeks to maximize

$$
E_{0} \sum_{-\infty} \beta^{t}\left(\log C_{t}-\chi \frac{N_{t}^{1+\phi}}{1+\phi}\right)
$$

where $C_{t}$ is a CES function over a continuum of goods with elasticity of substitution $\epsilon$, and $N_{t}$ denotes the fraction of household members who are employed. The latter must satisfy the constraint.

$$
0 \leq N_{t} \leq 1
$$

Note that such a specification of utility differs from the one generally used in the DMP model, where the marginal rate of substitution is generally assumed to be constant. Our specification is, instead, one often used in models of the business cycle, given its consistency with a balanced growth path and the direct parameterization of the Frisch labor supply elasticity by $\phi$.

\section{Technology}

We assume a continuum of firms indexed by $i \in[0,1]$, each producing a differentiated good. All firms have access to an identical technology

$$
Y_{t}(i)=A_{t} N_{t}(i)
$$


The variable $A_{t}$ represents the state of technology, which is assumed to be common across firms and to vary exogenously over time.

Employment in firm $i$ evolves according to

$$
N_{t}(i)=(1-\delta) N_{t-1}(i)+H_{t}(i)
$$

with $\delta \in(0,1)$ is an exogenous separation rate, and $H_{t}(i)$ represents the measure of workers hired by firm $i$ in period $t$.

\section{Labor Market}

Flows and Timing.

At the beginning of period $t$ there is a pool of jobless individuals who are available for hire, and whose size we denote by $U_{t}$. We refer to the latter variable as beginning-of-the period unemployment (or just unemployment, for short). We make assumptions below that guarantee full participation, i.e. at all times all individuals are either employed or willing to work, given the prevailing labor market conditions. Accordingly, we have

$$
U_{t}=1-(1-\delta) N_{t-1}
$$

Among those unemployed at the beginning of period $t$, a measure $H_{t} \equiv \int_{0}^{1} H(i) d i$ are hired and start working in the same period. Aggregate hiring evolves according to

$$
H_{t}=N_{t}-(1-\delta) N_{t-1}
$$

where $N_{t} \equiv \int_{0}^{1} N(i) d i$ denotes aggregate employment.

We introduce an index of labor market tightness, $x_{t}$, which we define as the ratio of aggregate hires to the unemployment rate

$$
x_{t} \equiv \frac{H_{t}}{U_{t}}
$$

The tightness index $x_{t}$ is assumed to lie within the interval $[0,1]$. Only workers 
in the unemployment pool at the beginning of the period can be hired $\left(H_{t} \leq U_{t}\right)$.

Note that, from the viewpoint of the unemployed, the index $x_{t}$ has an alternative interpretation: It is the probability of being hired in period $t$, or, in other words, the job-finding rate. Below we use the terms labor market tightness and jobfinding rate interchangeably.

\section{Hiring costs.}

Hiring labor is costly. Hiring costs for an individual firm are given by $G_{t} H_{t}(i)$, expressed in terms of the CES bundle of goods. $G_{t}$ represents the cost per hire, which is independent of $H_{t}(i)$ and taken as given by each individual firm.

While $G_{t}$ is taken as given by each firm, it is an increasing function of labor market tightness. Formally, we assume

$$
G_{t}=A_{t} B x_{t}^{\alpha}
$$

where $\alpha \geq 0$ and $B$ is a positive constant satisfying $\delta B<1$.

In our framework, the presence of hiring costs creates a friction in the labor market similar to the cost of posting a vacancy and the time needed to fill it in the standard DMP model. ${ }^{3}$

For future reference, it is useful to define an alternative measure of unemployment, denoted by $u_{t}$, and given by the fraction of the population who are left without a job after hiring takes place in period $t$. Formally, and given our assumption of full participation, we have

$$
u_{t}=1-N_{t}
$$

3. In our model, vacancies are assumed to be filled immediately by paying the hiring cost, which is a function of labor market tightness. In the DMP model, the hiring cost is uncertain, with its expected value corresponding to the (per period) cost of posting a vacancy times the expected time to fill it. This expected time is an increasing function of the ratio of vacancies to unemployment which can be expressed in turn as a function of labor market tightness. Thus, while the formalism used to capture the presence of hiring costs is different, both approaches have similar implications for firms' hiring decisions and unemployment dynamics. 


\subsection{The Constrained Efficient Allocation}

We derive the constrained-efficient allocation by solving the problem of a benevolent social planner who faces the technological constraints and labor market frictions that are present in the decentralized economy, but who internalizes the effect of variations in labor market tightness on hiring costs and, hence, on the resource constraint.

Given symmetry in preferences and technology, identical quantities of each good will be produced and consumed in the efficient allocation, i.e. $C_{t}(i)=C_{t}$ for all $i \in[0,1]$. Furthermore, since labor market participation has no individual cost but some social benefit (it lowers hiring costs, for any given level of employment and hiring), the social planner will choose an allocation with full participation.

Hence the social planner maximizes (1) subject to (2) and the aggregate resource constraint

$$
C_{t}=A_{t}\left(N_{t}-B x_{t}^{\alpha} H_{t}\right)
$$

where $H_{t}$ and $x_{t}$ are defined in (3) and (4).

The optimality condition for the social planner's problem can be written as

$$
\begin{aligned}
\frac{\chi C_{t} N_{t}^{\phi}}{A_{t}} \leq & 1-(1+\alpha) B x_{t}^{\alpha} \\
& +\beta(1-\delta) E_{t}\left\{\frac{C_{t}}{C_{t+1}} \frac{A_{t+1}}{A_{t}} B\left(x_{t+1}^{\alpha}+\alpha x_{t+1}^{\alpha}\left(1-x_{t+1}\right)\right)\right\}
\end{aligned}
$$

which must hold with equality if $N_{t}<1$.

Note that the left hand side of (6) represents the marginal rate of substitution between labor and consumption, whereas the right hand side captures the corresponding marginal rate of transformation, both normalized by productivity $A_{t}$. The latter has two components, captured by the two right-hand side terms. The first term corresponds to the additional output, net of hiring costs, generated by a marginal employed worker. The second captures the savings in hiring costs resulting from the reduced hiring needs in period $t+1 .^{4}$

4. Note that hiring costs (normalized by productivity) at time $t$ are given by $B x_{t}^{\alpha} H_{t}$. The 
- Consider first the case no hiring costs (i.e. $B=0$ ). In that case we have $C_{t}=A_{t} N_{t}$, with the efficiency condition (6) simplifying to

$$
\chi N_{t}^{1+\phi} \leq 1
$$

thus implying a level of employment invariant to technology shocks. This invariance is the result of offsetting income and substitution effects on labor supply, and is standard in this class of models. Absent capital accumulation, consumption increases in proportion to productivity; given a specification of preferences consistent with balanced growth, this increase in consumption leads to an income effect that exactly offsets the substitution effect.

- In the presence of hiring costs $(B>0)$, it is easy to check that the solution to (6) still implies a constant level of employment,

$$
N^{*}=\frac{x^{*}}{\delta+(1-\delta) x^{*}} \equiv N\left(x^{*}\right)
$$

where $x^{*}$ is the efficient level for the tightness indicator, implicitly given as the solution to

$$
\left(1-\delta B x^{\alpha}\right) \chi N(x)^{1+\phi} \leq 1-(1-\beta(1-\delta))(1+\alpha) B x^{\alpha}-\beta(1-\delta) \alpha B x^{1+\alpha}
$$

We assume an interior solution $0<x^{*}<1$ for the previous equation (which must hence hold with equality). This in turn implies an interior solution for employment and unemployment. ${ }^{5}$

The levels of consumption and output are proportional to productivity,

term $B x_{t}^{\alpha}$ in (6) captures the increase in hiring costs resulting from an additional hire, keeping cost per hire unchanged. The term $\alpha B x_{t}^{\alpha}$ reflects the effect on hiring costs of the change in the tightness index $x_{t}$ induced by an additional hire (given $H_{t}$ ). The savings in hiring costs at $t+1$ also have two components, both of which are proportional to $1-\delta$, the decline in required hiring. The first component, $B x_{t+1}^{\alpha}$, captures saving resulting from a lower $H_{t+1}$, given cost per hire. The (negative) term $\alpha B x_{t}^{c r}\left(1-x_{t+1}\right)$ adjusts the first component to take into account the lower cost per hire brought about by a smaller $x_{t+1}$ (the effect of lower required hires $H_{t+1}$ more than offsetting the smaller unemployment pool $\left.U_{t+1}\right)$.

5. A sufficient condition for an interior solution to (8) is given by $\chi(1-\delta B)>1-B$. That condition will be satisfied for any given values for $\delta$ and $B$, as long as $\chi$ is sufficiently close to (but below) one. 


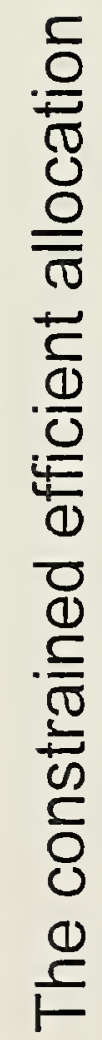

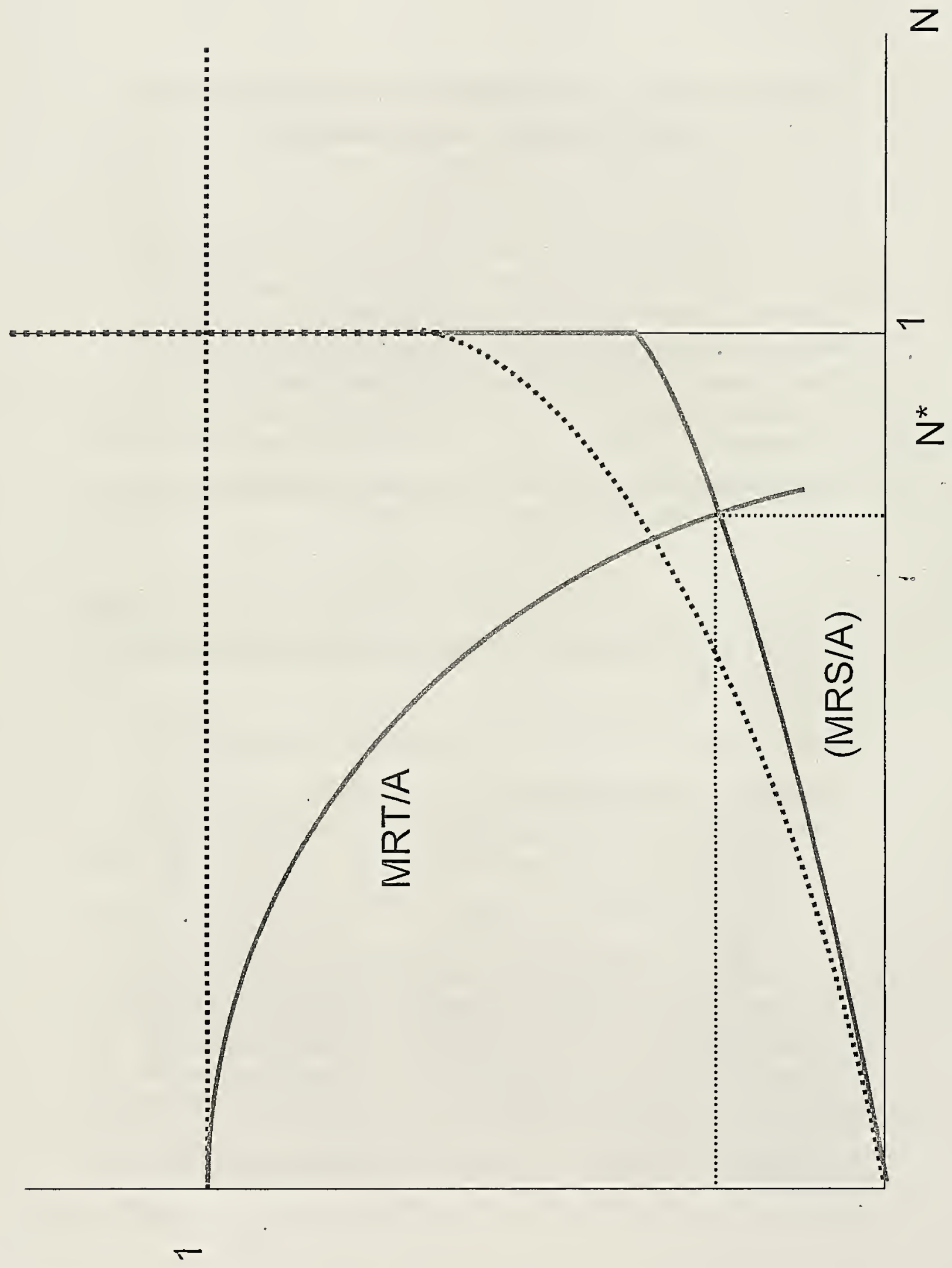


and given by $C_{t}^{*}=A_{t} N^{*}\left(1-\delta B x^{* \alpha}\right)$ and $Y_{t}^{*}=A_{t} N^{*}$.

Figure 1 shows graphically the determinants of the efficient level of employment in our model. The dashed (blue) lines represent the efficiency condition in the case of no hiring costs, while the solid (red) lines correspond to the model with hiring costs. The upward sloping schedules starting off the origin correspond to the left hand side of (7) and (8), respectively, normalized by productivity. They represent the (normalized) marginal rate of substitution $\chi\left(C_{t} / A_{t}\right) N^{\phi}$, as a function of the (constant) level of employment $N$. Note that the red schedule is uniformly below the blue one, due to the downward adjustment of consumption by a factor $\left(1-\delta B x^{\alpha}\right)$ resulting from the diversion of a fraction of output to hiring costs. The schedules originating at $(0,1)$ correspond to the right hand side of (7) and (8), and capture the marginal rate of transformation between employment and consumption (again, normalized by productivity), as a function of employment. It is constant (and equal to one) in the case of no hiring costs, but declining when hiring costs are present, capturing the fact that the increase in employment needed to produce an additional unit of consumption is increasing, as a result of the increasing level of hiring costs.

Having characterized the constrained-efficient allocation we next turn our attention to the analysis of equilibrium in the decentralized economy. We consider first the case of flexible prices.

\section{$3 \quad$ Equilibrium under Flexible Prices}

We start looking at the problem facing firms. The solution to that problem describes the equilibrium, given the wage. Then we characterize the equilibrium under two alternative models of wage determination.

\subsection{Value Maximization by Firms}

We first look at firms' behavior, given the wage. Each firm produces a differentiated good, whose price it sets optimally each period, given demand. Formally, 
the firm maximizes its value

$$
E_{t} \sum_{k} Q_{t, t+k}\left(P_{t+k}(i) Y_{t+k}(i)-P_{t+k} W_{t+k} N_{t+k}(i)-P_{t+k} G_{t+k} H_{t+k}(i)\right)
$$

subject to the sequence of demand constraints

$$
Y_{t}(i)=\left(\frac{P_{t}(i)}{P_{t}}\right)^{-\epsilon}\left(C_{t}+G_{t} H_{t}\right)
$$

for $t=0,1,2, \ldots$ and taking as given the paths for the aggregate price level $P_{t}$, the (real) wage $W_{t}$, and unit hiring costs $G_{t}$, and where $Q_{t, t+k} \equiv \beta^{k} \frac{C_{t}}{C_{t+k}} \frac{P_{t}}{P_{t+k}}$ is the stochastic discount factor for nominal payoffs.

The optimal price setting rule associated with the solution to the above problem takes the form:

$$
P_{t}(i)=\mathcal{M} P_{t} M C_{t}
$$

for all $t$, where $\mathcal{M} \equiv \frac{\epsilon}{\epsilon-1}$ is the optimal markup and

$$
M C_{t}=\frac{W_{t}}{A_{t}}+B x_{t}^{\alpha}-\beta(1-\delta) E_{t}\left\{\frac{C_{t}}{C_{t+1}} \frac{A_{t+1}}{A_{t}} B x_{t+1}^{\alpha}\right\}
$$

is the firm's (real) marginal cost. The latter depends on the wage normalized by productivity, as well as on current and expected hiring costs. In particular, marginal cost increases with current labor market tightness (due to the induced higher hiring costs), but it decreases with the expected tightness index, since a higher value for the latter implies larger savings in next period's hiring costs if the firm decides to increase its current employment. ${ }^{6}$

In a symmetric equilibrium we must have $P_{t}(i)=P_{t}$ for all $i \in[0,1]$, and hence (9) implies

$$
M C_{t}=\frac{1}{\mathcal{M}}
$$

6. Rotemberg and Woodford (1999) were among the first to point out the implications of hiring costs for the construction of marginal cost measures. They assumed hiring costs were internal to the firm and took the form of a quadratic function of the change in employment. 
for all $t$. Combining (10) and (11) and rearranging terms we obtain

$$
\frac{W_{t}}{A_{t}}=\frac{1}{\mathcal{M}}-B x_{t}^{\alpha}+\beta(1-\delta) E_{t}\left\{\frac{C_{t}}{C_{t+1}} \frac{A_{t+1}}{A_{t}} B x_{t+1}^{\alpha}\right\}
$$

A characterization of the equilibrium requires a specification of wage determination. We start by assuming Nash bargaining.

\subsection{Equilibrium with Nash Bargained Wages}

Let $\mathcal{W}_{t}^{N}$ and $\mathcal{W}_{t}^{U}$ denote the value to the representative household of having a marginal member employed or unemployed at the beginning of period $t$, both expressed in consumption units. The value of a (marginal) employment relationship is given by

$$
\begin{aligned}
\mathcal{W}_{t}^{N}= & W_{t}-\chi C_{t} N_{t}^{\varphi} \\
& +\beta E_{t}\left\{\frac{C_{t}}{C_{t+1}}\left[\left(1-\delta\left(1-x_{t+1}\right)\right) \mathcal{W}_{t+1}^{N}+\delta\left(1-x_{t+1}\right) \mathcal{W}_{t+1}^{U}\right]\right\}
\end{aligned}
$$

i.e. the sum of the current payoffs (the wage minus the marginal rate of substitution) and the discounted expected continuation values, with $\delta\left(1-x_{t+1}\right)$ is the probability of being unemployed in period $t+1$, conditional on being employed at time $t$.

The corresponding value from a member who remains unemployed after hiring has taken place is:

$$
\mathcal{W}_{t}^{U}=\beta E_{t}\left\{\frac{C_{t}}{C_{t+1}}\left[x_{t+1} \mathcal{W}_{t+1}^{N}+\left(1-x_{t+1}\right) \mathcal{W}_{t+1}^{U}\right]\right\}
$$

Combining both conditions we obtain the household's surplus from an established job relationship:

$$
\begin{aligned}
\mathcal{W}_{t}^{N}-\mathcal{W}_{t}^{U}= & W_{t}-\chi C_{t} N_{t}^{\varphi} \\
& +\beta(1-\delta) E_{t}\left\{\frac{C_{t}}{C_{t+1}}\left(1-x_{t+1}\right)\left(\mathcal{W}_{t+1}^{N}-\mathcal{W}_{t+1}^{U}\right)\right\}
\end{aligned}
$$


On the other hand the firm's surplus from an established relationship is simply given by the hiring cost $G_{t}$, since a firm can always replace a worker at that cost (with no search time required).

Letting $\vartheta$ denote the relative weight of workers in the Nash bargain, the latter requires

$$
\mathcal{W}_{t}^{N}-\mathcal{W}_{t}^{U}=\vartheta G_{t}
$$

Imposing the latter condition in (13), and rearranging terms, we obtain the Nash wage schedule:

$$
\frac{W_{t}}{A_{t}}=\frac{\chi C_{t} N_{t}^{\varphi}}{A_{t}}+\vartheta B x_{t}^{\alpha}-\beta(1-\delta) E_{t}\left\{\frac{C_{t}}{C_{t+1}} \frac{A_{t+1}}{A_{t}}\left(1-x_{t+1}\right) \vartheta B x_{t+1}^{\alpha}\right\}
$$

Equation (14) can now be used to substitute out $W_{t}$ in (12), with the resulting equilibrium under Nash bargaining being described by

$$
\begin{aligned}
\frac{\chi C_{t} N_{t}^{\phi}}{A_{t}}= & \frac{1}{\mathcal{M}}-(1+\vartheta) B x_{t}^{\alpha} \\
& +\beta(1-\delta) E_{t}\left\{\frac{C_{t}}{C_{t+1}} \frac{A_{t+1}}{A_{t}} B\left(x_{t+1}^{\alpha}+\vartheta x_{t+1}^{\alpha}\left(1-x_{t+1}^{\alpha}\right)\right)\right\}
\end{aligned}
$$

together with (3), (4), and (5), and given an exogenous process for technology.

It is easy to verify that the equilibrium under Nash bargained wages involves a constant level of employment:

$$
N^{n b}=\frac{x^{n b}}{\delta+(1-\delta) x^{n b}} \equiv N\left(x^{n b}\right)
$$

where $x^{n b}$ is the (constant) equilibrium job finding rate, implicitly given by the solution to:

$$
\chi\left(1-\delta B x^{\alpha}\right) N(x)^{1+\phi}=\frac{1}{\mathcal{M}}-(1-\beta(1-\delta))(1+\vartheta) B x^{\alpha}-\beta(1-\delta) \vartheta B x^{\alpha}
$$


and where consumption and output are proportional to productivity, and given by $C_{t}^{n b}=A_{t}\left(1-\delta B\left(x^{n b}\right)^{\alpha}\right) N^{n b}$ and $Y_{t}^{n b}=A_{t} N^{n b}$.

Finally, imposing the equilibrium conditions in (14), we obtain an expression for the equilibrium Nash bargained wage:

$$
\frac{W_{t}^{n b}}{A_{t}}=\frac{1}{\mathcal{M}}-(1-\beta(1-\delta)) B\left(x^{n b}\right)^{\alpha}
$$

Note that, under our assumptions, productivity shocks are reflected one-for-one in the Nash bargained wage and thus have no effect on employment. That result is independent of the elasticity of hiring costs with respect to $x_{t}$ or the relative weight of workers in the Nash bargain. Such a result stands in contrast to Shimer (2005). The reason is that, in line with the DMP framework, Shimer assumes linear preferences and, hence, a marginal rate of substitution that is invariant to changes in productivity. In that context, an increase in productivity leads to a less than one-for-one increase in the Nash bargained wage, increasing profits and inducing frms to create new jobs. Shimer then shows that, under plausible assumptions about the matching function and the relative bargaining strength of workers and firms, the employment response is likely to be small.

Our model allows instead for concave preferences and an endogenous marginal rate of substitution between consumption and labor. Under our-standard-utility specification, the Nash bargained wage increases one-for-one with the marginal rate of substitution (which, in turn, increases with productivity), at any given level of employment. Thus, changes in productivity have no effect on (un)employment, independently of the hiring function, or the relative bargaining of workers and firms. ${ }^{7}$

In a way analogous to the standard DMP model (see Hosios (1990)), one can derive the conditions under which the equilibrium with Nash bargaining will cor-

7. Notice however that the equal increase in $C$ and $W$ is the result of both our specification of preferences and the absence of capital accumulation. In the presence of capital accumulation, employment would typically move, as it does in conventional real business cycle models. 
respond to the constrained efficient allocation. To see this, we just need to compare equilibrium condition (15) with condition (6) characterizing the constrained efficient (interior) allocation, and which we rewrite here for convenience:

$\frac{\chi C_{t} N_{t}^{\phi}}{A_{t}}=1-(1+\alpha) B x_{t}^{\alpha}+\beta(1-\delta) E_{t}\left\{\frac{C_{t}}{C_{t+1}} \frac{A_{t+1}}{A_{t}} B\left(x_{t+1}^{\alpha}+\alpha x_{t+1}^{\alpha}\left(1-x_{t+1}\right)\right)\right\}$

The two equations are equivalent if and only if the following two conditions are satisfied:

First, $\mathcal{M}=1$ must hold. In other words we must have perfect competition in the goods market (or alternatively, a production subsidy which exactly offsets the market power distortion).

Second, the workers' relative share of the surplus in the Nash bargain, $\vartheta$, must coincide with the elasticity of the hiring cost function, $\alpha$. That requirement is analogous to the Hosios condition found in the standard DMP framework, which requires that the share of workers in the Nash bargain corresponds to the elasticity of the matching function with respect to unemployment.

Figures 2 and 3 show graphically the factors behind the equilibrium under Nash bargaining, and contrasts them with those underlying the constrained efficient allocation. The latter is represented by the intersection of the solid (red) lines, which match those in Figure 1, already discussed above.

The downward sloping dashed line gives the ratio $W_{t} / A_{t}$ implied by price setting, equation (10), after imposing $M C_{t}=1 / \mathcal{M}$, and evaluated at a constant employment allocation (constant over time). It can be interpreted as a labor demand schedule, determining the (constant) level of employment consistent with value maximization by firms, as a function of the (productivity adjusted) wage. Its slope becomes steeper with $B$, while its curvature increases with $\alpha$. Note also that the schedule is flatter than its counterpart in the social planner problem, reflecting the fact that in the decentralized economy firms do not take into account the effects of their hiring decisions on hiring costs.

The upward sloping dashed (green) line gives $W_{t} / A_{t}$ implied by the Nash wage 


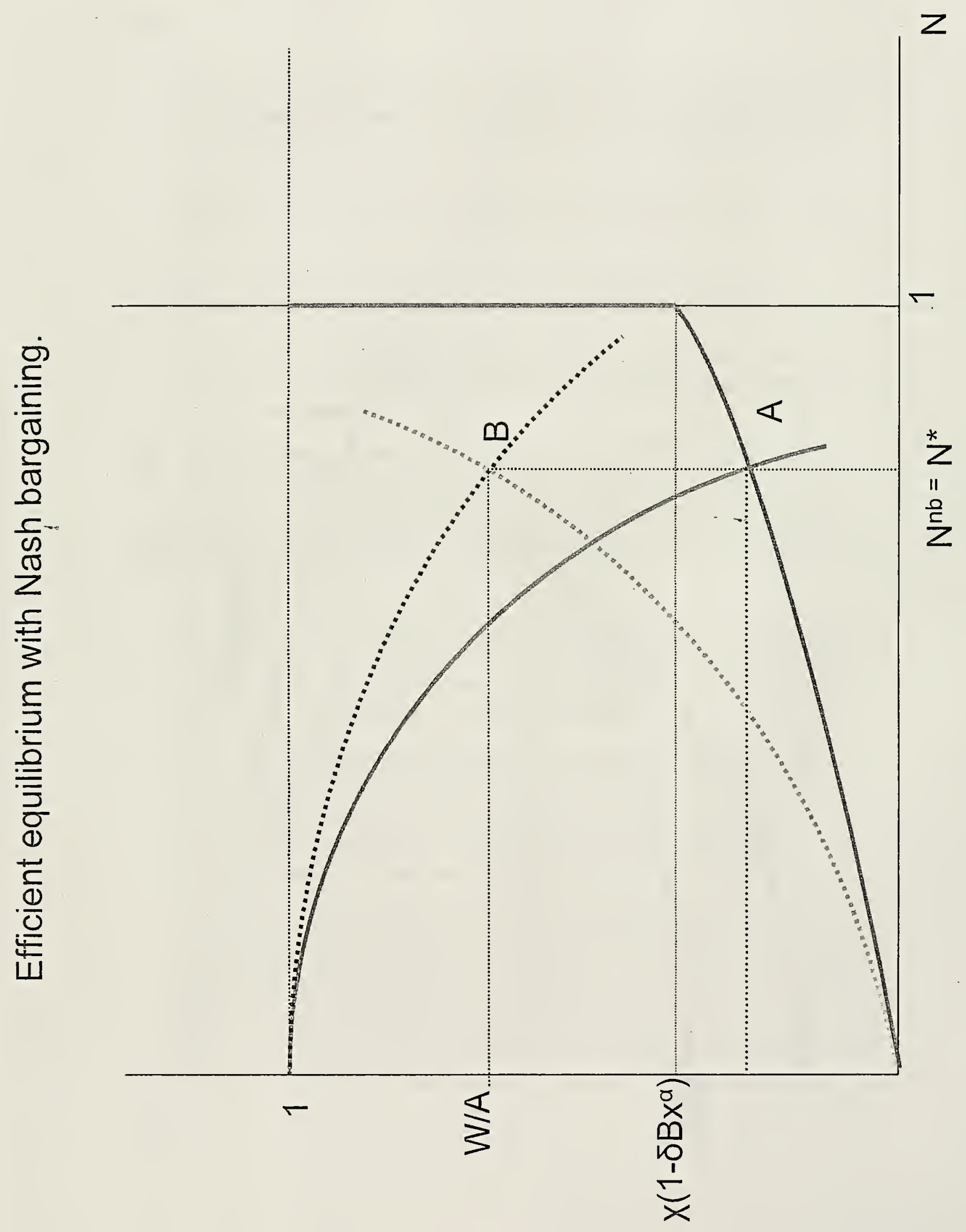


schedule (14), evaluated at a constant employment allocation. Its slope is increasing in $\vartheta$, workers' relative weight in the Nash bargain. Its position above the red line reflects workers ' bargaining power.

Figure 2 represents an equilibrium characterized by inefficiently high unemployment. This is a consequence of two factors: (i) a positive markup in the goods market (which shifts the labor demand schedule downward), and (ii) too much bargaining power by workers $(\vartheta>\alpha)$ which makes the wage schedule too steep. As a result we have $N^{n b}<N^{*}$, which implies an inefficiently high unemployment level.

Figure 3 illustrates graphically an equilibrium which leads to an efficient unemployment level. Two assumptions are needed for this, as discussed earlier. First, we have $\mathcal{M}=1$. Second, the slope of the upward sloping wage schedule (determined by $\vartheta$ ) exactly offsets the flatter labor demand schedule (whose slope is determined by $\alpha$ ), making both intersect at $N^{*}$.

We restrict ourselves to equilibria in which the wage remains above the marginal rate of substitution when the latter is evaluated at full employment:

$$
\frac{W_{t}}{A_{t}}>\chi(1-\delta B)
$$

for all $t$. This condition guarantees full participation (as all the unemployed would rather work than not), and that those without a job in any given period are involuntarily unemployed. Thus, any inefficiency in the equilibrium level of employment cannot be attributed to an inefficiently low labor supply. ${ }^{8}$ Note that it is only because of the presence of hiring costs that this is consistent with the private efficiency of existing employment relationships. ${ }^{9}$

8. This is in contrast with standard RBC or NK models, in which suboptimal levels of enployment are also associated with an inefficiently low labor supply.

9. In the absence of such frictions any unemployed worker would be willing to offer his labor services at a wage slightly lower than that of an employed worker (from a different household), which would bid down the wage up to the point where (18) held with equality. 


\subsection{Equilibrium under Real Wage Rigidities}

As shown in the previous section, the equilibrium wage under Nash bargaining moves one-for-one with productivity variations. As a result, changes in productivity do not affect firms' incentives to change the rate at which workers are hired, leaving unemployment unchanged. In our model, that invariance result holds independently of the elasticity of the hiring cost function and the Nash weights, and hence, independently of whether the equilibrium supports the efficient allocation or not.

Following Hall (2005) and Blanchard and Galí (2005), we examine in this section the consequences of real wage rigidity on employment and unemployment. More precisely, and to keep the analysis as simple as possible, we assume a wage schedule of the form

$$
W_{t}=\Theta A_{t}^{1-\gamma}
$$

where $\gamma \in[0,1]$ is an index of real wage rigidities and $\Theta>0$ is a constant that determines the real wage, and hence employment in the steady state. Clearly, the above formulation is meaningful only if technology is stationary, an assumption we shall maintain here.

Note that for $\gamma=0$ (and setting $\Theta$ to the right hand side of (17)) the wage schedule corresponds to the Nash bargaining wage, for any given relative share $\vartheta$. At the other extreme, when $\gamma=1$, equation (19) corresponds to the canonical example of a rigid wage analyzed by Hall (2005). Also notice that if we assume that $\Theta=A^{\gamma}\left(1-(1-\beta(1-\delta)) g\left(x^{*}\right)\right)$ we allow for the possibility that the efficient steady state can be attained (if in addition $\mathcal{M}=1$.)

In addition to (18) we assume

$$
\frac{W_{t}}{A_{t}}<\frac{1}{\mathcal{M}}
$$

for all $t$, which guarantees that firms will want to employ some workers without incurring any losses.

Combining (19) with (12) we obtain the following difference equation representing 
the equilibrium under real wage rigidities.

$$
\Theta A_{t}^{-\gamma}=\frac{1}{\mathcal{M}}-B x_{t}^{\alpha}+\beta(1-\delta) E_{t}\left\{\frac{C_{t}}{C_{t+1}} \frac{A_{t+1}}{A_{t}} B x_{t+1}^{\alpha}\right\}
$$

The previous equation can be rearranged and solved forward to yield

$$
B x_{t}^{\alpha}=\sum_{k=0}^{\infty}(\beta(1-\delta))^{k} E_{t}\left\{\Lambda_{t, t+k}\left(\frac{1}{\mathcal{M}}-\Theta A_{t+k}^{-\gamma}\right)\right\}
$$

where $\Lambda_{t, t+k} \equiv\left(C_{t} / C_{t+k}\right)\left(A_{t+k} / A_{t}\right)$. We see that as long as wages are not fully flexible $(\gamma>0)$, variations in current or anticipated productivity will affect labor market tightness (or, equivalently, the job finding rate), with the size of the effect being a decreasing function of the sensitivity of hiring costs to labor market condition, as measured by parameter $\alpha$. In particular, a transitory increase in : productivity raises $x_{t}$ temporarily, which implies a decrease in unemployment, followed by an eventual return to its normal level.

From the analysis above it follows that in the presence of real wage rigidities the equilibrium will be characterized by inefficient fluctuations in (un)employment. We defer a full characterization of these fluctuations to later, after we have introduced sticky prices and a role for monetary policy (Under a particular monetary policy, namely inflation targeting, the outcome for real variables is the same as in the economy without nominal rigidities.)

\section{$4 \quad$ Introducing Sticky Prices}

Following much of the recent literature on monetary business cycle models, we introduce sticky prices in our model with labor market frictions using the formalism due to Calvo (1983). Each period only a fraction $1-\theta$ of firms, selected randomly, reset prices. The remaining firms, with measure $\theta$, keep their prices uncharged. 
As shown in Appendix A, the optimal price setting rule for a firm resetting prices in period $t$ is given by

$$
E_{t}\left\{\sum_{k=0}^{\infty} \theta^{k} Q_{t, t+k} Y_{t+k \mid t}\left(P_{t}^{*}-\mathcal{M} P_{t+k} M C_{t+k}\right)\right\}=0
$$

where $P_{t}^{*}$ denotes the price newly set by at time $t, Y_{t+k \mid t}$ is the level of output in period $t+k$ for a firm resetting its price in period $t$, and $\mathcal{M} \equiv \frac{\epsilon}{\epsilon-1}$ is the gross desired markup. The real marginal cost is now given by

$$
M C_{t}=\Theta A_{t}^{-\gamma}+B x_{t}^{\alpha}-\beta(1-\delta) E_{t}\left\{\frac{C_{t}}{C_{t+1}} \frac{A_{t+1}}{A_{t}} B x_{t+1}^{\alpha}\right\}
$$

is the firm's real marginal cost in period $t$.

The two previous equations embody the essence of our integration:

- The optimal price setting equation (22) takes the same form as in the standard Calvo model; given the path of marginal costs: it leads firms to choose a price that is a weighted average of current and expected marginal costs, with the weights being a function of $\theta$, the price stickiness parameter.

- The marginal cost is, however, influenced by the presence of labor market frictions (as captured by hiring cost parameters $B$ and $\alpha$ ) and real wage rigidities (measured by $\gamma$ ).

To make progress requires log-linearizing the system, the task to which we turn.

\subsection{Log-linearized Equilibrium Dynamics}

The first step is to derive the equation characterizing inflation. Log-linearization around a zero inflation steady state of the optimal price setting rule (22) and the price index equation $P_{t}=\left((1-\theta)\left(P_{t}^{*}\right)^{1-\epsilon}+\theta\left(P_{t-1}\right)^{1-\epsilon}\right)^{\frac{1}{1-\epsilon}}$, yields the standard inflation dynamics equation ${ }^{10}$

$$
\pi_{t}=\beta E_{t}\left\{\pi_{t+1}\right\}+\lambda \widehat{m c}_{t}
$$

10. See, e.g., Gali and Gertler (1999) for a derivation. 
where $\widehat{m c}_{t} \equiv \log \left(M C_{t} / M C\right)=\log \left(\mathcal{M} M C_{t}\right)$ represent the $\log$ deviations of real marginal cost from its steady state value and $\lambda \equiv(1-\beta \theta)(1-\theta) / \theta$.

The second step is to derive the equation characterizing marginal cost. Letting $\widehat{x}_{t}=\log \left(x_{t} / x\right), \widehat{c}_{t}=\log \left(C_{t} / C\right)$, and $g \equiv B x^{\alpha}$ we can write the first-order Taylor expansion of (23) as

$$
\widehat{m c}_{t}=\alpha g \mathcal{M} \widehat{x}_{t}-\beta(1-\delta) g \mathcal{M} E_{t}\left\{\left(\widehat{c}_{t}-a_{t}\right)-\left(\widehat{c}_{t+1}-a_{t+1}\right)+\alpha \widehat{x}_{t+1}\right\}-\Phi \gamma a_{t}
$$

where $\Phi \equiv \mathcal{M} W / A=1-(1-\beta(1-\delta)) g \mathcal{M}<1$, and where we have normalized the steady state productivity to unity $(A=1)$, letting $a_{t} \equiv \log A_{t}$ denote $\log$ deviations of productivity from that steady state.

The third step, using (4) and (5), and letting $\widehat{n}_{t}=\log \left(N_{t} / N\right)$ is to derive the log linear approximations for labor market tightness and consumption:

$$
\begin{gathered}
\delta \widehat{x}_{t}=\widehat{n}_{t}-(1-\delta)(1-x) \widehat{n}_{t-1} \\
\widehat{c}_{t}=a_{t}+\frac{1-g}{1-\delta g} \widehat{n}_{t}+\frac{g(1-\delta)}{1-\delta g} \widehat{n}_{t-1}-\frac{\alpha g}{1-\delta g} \delta \widehat{x}_{t}
\end{gathered}
$$

The last step is to use the linearized first order conditions of the consumer (which we have ignored until now) to get:

$$
\widehat{c}_{t}=E_{t}\left\{\widehat{c}_{t+1}\right\}-\left(i_{t}-E_{t}\left\{\pi_{t+1}\right\}-r_{t}^{*}\right)
$$

where $i_{t}$ denotes the short-term nominal interest rate and $r_{t}^{*} \equiv \rho-a_{t}+E_{t}\left\{a_{t+1}\right\}$, $\rho \equiv-\log \beta$, is the interest rate that supports the efficient allocation.

The equilibrium of the model with wage rigidities is fully characterized by equations (24) to (28), together with a process for productivity, and a description of monetary policy. 


\subsection{Approximate Log-linearized Dynamics}

The characterization we have just given can however be simplified considerably under two further approximations, which we view as reasonable:

The first is that hiring costs are small relative to output, so we can approximate consumption by $\widehat{c}_{t}=a_{t}+\widehat{n}_{t}{ }^{11}$.

The second is that fluctuations in $\widehat{x}_{t}$ are large relative to those in $\widehat{n}_{t}$, an approximation which follows from (26) and the assumption of a low separation rate. ${ }^{12}$ Combined with our first assumption this allows one to drop the term $\widehat{c}_{t}-a_{t}$ and its lead from the expression for marginal cost (25).

These two approximations imply that we can rewrite the expression for marginal cost, equation (25), as:

$$
\widehat{m c_{t}}=\alpha g \mathcal{M}\left(\widehat{x}_{t}-\beta E_{t}\left\{\widehat{x}_{t+1}\right\}\right)-\Phi \gamma a_{t}
$$

These approximations and this expression for marginal cost allow us in turn to derive the following characterization of the economy:

- First, combining equation (29) with equation (24) gives a relation between inflation, current labor market tightness and current and expected productivity:

$$
\pi_{t}=\alpha g \mathcal{M} \lambda \widehat{x}_{t}-\lambda \Phi \gamma \sum_{k=0}^{\infty} \beta^{k} E_{t}\left\{a_{t+k}\right\}
$$

Note that, despite the fact that expected infation does not appear in (30), inflation is a forward looking variable, through its dependence on current and future $a_{t}$ 's, and current $x_{t}$, which itself depends on current and expected real marginal costs. ${ }^{13}$

11. More precisely we assume that $g$ and $\delta$ are of the same order of magnitude as fluctuations in $\widehat{n}_{t}$, implying that terms involving $g \widehat{n}_{t}$ or $\delta \widehat{n}_{t}$ are of second order.

12. In other words, (26) implies that $\delta \widehat{x}_{t}$ is of the same order of magnitude as $\widehat{n}_{t}$ and, hence, it cannot be dropped from our linear approximations. We assume the same is true for terms in $g \widehat{x}_{t}$ (i.e., we assume that $\delta$ and $g$ have the same order of magnitude).

13. This can be seen by solving (29) forward, to get $\alpha g \mathcal{M} \widehat{x}_{t}=\sum_{k=0}^{\infty} \beta^{k} E_{t}\left\{\widehat{m c}_{t+k}+\Phi \gamma a_{t+k}\right\}$. 
- Second, let $\widehat{u}_{t} \equiv u_{t}-u$ denote the deviations of the unemployment rate (after hiring) from its steady state value, $u=(\delta(1-x)) /(x+\delta(1-x))$. Then, using equation (26) and the approximation $\widehat{u}_{t}=-(1-u) \widehat{n}_{t}$, gives us a relation between labor market tightness and the unemployment rate:

$$
\widehat{u}_{t}=(1-\delta)(1-x) \widehat{u}_{t-1}-(1-u) \delta \widehat{x}_{t}
$$

- Third, using the log-linearized Euler equation of the consumer, together with the approximation $\widehat{c}_{t}=\widehat{n}_{t}+a_{t}$, and the approximation $\widehat{u}_{t}=-(1-u)$ $\widehat{n}_{t}$ gives a relation between the unemployment rate and the real interest rate:

$$
\widehat{u}_{t}=E_{t}\left\{\widehat{u}_{t+1}\right\}+(1-u)\left(i_{t}-E_{t}\left\{\pi_{t+1}\right\}-r_{t}^{*}\right)
$$

where, as before, $i_{t}$ is the short-term nominal interest rate and $r_{t}^{*} \equiv \rho-$ $a_{t}+E_{t}\left\{a_{t+1}\right\}$, with $\rho \equiv-\log \beta$. Note that (12) relates the unemployment rate to current and anticipated deviations of the real interest rate from its efficient counterpart.

These equations, together with a specification of monetary policy, fully characterize the equilibrium. We shall look at the implications of alternative monetary policies in the next section. We limit ourselves here to a few remarks about the relation between inflation and unemployment:

Assume that productivity follows a stationary AR(1) process with autoregressive parameter $\rho_{a} \in[0,1)$. We can then rewrite (30) as:

$$
\pi_{t}=\alpha g \mathcal{M} \lambda \widehat{x}_{t}-\Psi \gamma a_{t}
$$

where $\Psi \equiv \lambda \Phi /\left(1-\beta \rho_{a}\right)>0$.

Using the relation between labor market tightness and unemployment, we can then derive a "Phillips curve" relation between inflation and unemployment:

$$
\pi_{t}=-\kappa \widehat{u}_{t}+\kappa(1-\delta)(1-x) \widehat{u}_{t-1}-\Psi \gamma a_{t}
$$


where $\kappa \equiv \alpha g \mathcal{M} \lambda / \delta(1-u)$. Or equivalently

$$
\pi_{t}=-\kappa(1-(1-\delta)(1-x)) \widehat{u}_{t}-\kappa(1-\delta)(1-x) \Delta u_{t}-\Psi \gamma a_{t}
$$

which highlights the negative dependence of inflation on both the level and the change in the unemployment rate.

Given that constrained efficient unemployment is constant, it would be best to stabilize both unemployment and inflation. Note however that, to the extent that the wage does not adjust fully to productivity changes $(\gamma>0)$, it is not possible for the monetary authority to fully stabilize both unemployment and inflation simultaneously. There is, to use the terminology introduced by Blanchard and Galí (2005), no divine coincidence.

The reason is the same as in our earlier paper, the fact that productivity shocks affect the wedge between the natural rate-the unemployment rate that would prevail absent nominal rigidities-and the constrained efficient unemployment rate. Stabilizing inflation, which is equivalent to stabilizing unemployment at its natural rate, does not deliver constant unemployment. Symmetrically, stabilizing unemployment does not deliver constant inflation.

The next section examines the implications of alternative monetary policy regimes.

\section{$5 \quad$ Monetary Policy, Sticky Prices and Real Wage Rigidities}

\subsection{Two Extreme Policies}

We start by discussing two simple, but extreme, policies and their outcomes for inflation and unemployment, leaving the derivation of the optimal policy for the next subsection. ${ }^{14}$ Given the paths of inflation and unemployment implied by each policy regime, equation (32) can be used to determine the interest rate rule that would implement the corresponding allocation.

14. Throughout we rely on the log-linear approximations made in the previous section. 
Unemployment stabilization. Recall that in the constrained efficient allocation unemployment is constant. A policy that seeks to stabilize the gap between unemployment and its efficient level requires therefore that $\widehat{u}_{t}=\widehat{n}_{t}=\widehat{x}_{t}=0$ for all $t$, and hence

$$
\pi_{t}=-\Psi \gamma a_{t}
$$

Note that, given $\Psi$ (which is a function of underlying parameters other than $\gamma$ ), the size of the implied fluctuations in inflation is increasing in the degree of wage rigidities $\gamma \cdot{ }^{15}$

Strict inflation targeting. Setting $\pi_{t}=0$ in (34) we can determine the evolution of the unemployment rate under strict inflation targeting:

$$
\widehat{u}_{t}=(1-\delta)(1-x) \widehat{u}_{t-1}-(\Psi \gamma / \kappa) a_{t}
$$

Note that the previous equation also characterizes the evolution of unemployment under flexible prices, since the allocation consistent with price stability replicates the one associated with the flexible price equilibrium. ${ }^{16}$

Equation (35) shows that under a strict inflation targeting policy, the unemployment rate will display some intrinsic persistence, i.e. some serial correlation beyond that inherited from productivity. The degree of intrinsic persistence depends critically on the separation rate $\delta$ and the steady state job finding rate $x$, while the amplitude of fluctuations are increasing in $\gamma$, the degree of real rigidities. In a sclerotic labor market, with high average unemployment and a a low average job finding rate $x$, unemployment will display strong persistence, well beyond that inherited from productivity. More active labor markets, on the other

15. Intuitively, the stabilization of unemployment (and hiring costs) makes the real marginal cost vary with productivity, according to $\widehat{m c}_{t}=-\Phi \gamma a_{t}$, generating fluctuations in inflation. The amplitude of those fluctuations is increasing in the degree of wage rigidities $\gamma$ and in the persistence of the shock to productivity $\rho_{a}$, but decreasing in the degree of nominal rigidities (which is inversely related to $\lambda$ ).

16. The full stabilization of prices requires that firms markups are stabilized at their desired level or, equivalently, that the real marginal cost remains constant at its steady state level, i.e. $\widehat{m c}_{t}=0$ for all $t$. In the presence of less than one-for-one adjustment of wages to changes in productivity, that requires an appropriate adjustment in the degree of labor market tightness and, hence, in unemployment. 
hand, will be characterized by a high average job finding rate, and will display less persistent unemployment fluctuations under the stric inflation targeting policy. ${ }^{17}$

\subsection{Optimal Monetary Policy}

In this section we analyze the nature of the optimal monetary policy in our model.

To simplify the analysis and avoid well understood but peripheral issues, we assume the unemployment fluctuates around a steady state value which corresponds to that of the constrained efficient allocation. As shown in Appendix B, a second order approximation to the welfare losses of the representative household around that steady state is proportional to:

$$
E_{0} \sum_{t=0}^{\infty} \beta^{t}\left(\pi_{t}^{2}+\alpha_{u} \widehat{u}_{t}^{2}\right)
$$

where $\alpha_{u} \equiv \lambda(1+\phi) \chi\left(N^{*}\right)^{\phi-1} / \epsilon>0$.

Hence the monetary authority will seek to minimize (36) subject to the sequence of equilibrium constraints given by (34), for $t=0,1,2, \ldots$ Clearly, and given the form of the welfare loss function the optimal policy will be somewhere between the two extreme policies discussed above.

The first order conditions for the above problem take the following form:

$$
\begin{gathered}
\pi_{t}=\zeta_{t} \\
\alpha_{u} \widehat{u}_{t}=\kappa \zeta_{t}-\beta(1-\delta)(1-x) \kappa E_{t}\left\{\zeta_{t+1}\right\}
\end{gathered}
$$

for $t=0,1,2, \ldots$ where $\zeta_{t}$ is the Lagrange multiplier associated with period $t$ constraint. Combining both conditions to eliminate the multiplier gives the optimal targeting rule: ${ }^{18}$

$$
\pi_{t}=\beta(1-\delta)(1-x) E_{t}\left\{\pi_{t+1}\right\}+\left(\alpha_{u} / \kappa\right) \widehat{u}_{t}
$$

17. The hypothesis that more sclerotic markets might lead to more persistence to unemployment was explored empirically by Barro (1988).

18. Note that when $\alpha_{u}$ corresponds to utility maximization we have $\frac{\alpha_{u}}{\kappa}=\frac{\delta(1+\phi)(1-u)^{\phi}}{\alpha g \epsilon}$ 
Equivalently, and solving forward,

$$
\pi_{t}=\left(\frac{\alpha_{u}}{\kappa}\right) \sum_{t=0}^{\infty}(\beta(1-\delta)(1-x))^{k} E_{t}\left\{\widehat{u}_{t+k}\right\}
$$

Hence in response to an adverse productivity shock, the central bank should partly accommodate the inflationary pressures, while letting unemployment increase up to the point where its anticipated path satisfies (38).

Combining (37) and (34) we can derive a second order difference equation describing the optimal evolution of the unemployment rate as a function of productivity:

$$
\widehat{u}_{t}=q \widehat{u}_{t-1}+\beta q E_{t}\left\{\widehat{u}_{t+1}\right\}-s a_{t}
$$

where

$$
q \equiv \frac{\kappa^{2}(1-\delta)(1-x)}{\alpha_{u}+\kappa^{2}\left(1+\beta(1-\delta)^{2}(1-x)^{2}\right)} \in(0,1)
$$

and

$$
s \equiv \frac{\kappa\left(1-\beta(1-\delta)(1-x) \rho_{a}\right) \Psi \gamma}{\alpha_{u}+\kappa^{2}\left(1+\beta(1-\delta)^{2}(1-x)^{2}\right)}>0
$$

The unique stationary solution to that difference equation is given by:

$$
\widehat{u}_{t}=\psi_{u} \widehat{u}_{t-1}-\psi_{a} a_{t}
$$

where

$$
\psi_{u} \equiv \frac{1-\sqrt{1-4 \beta q^{2}}}{2 q \beta} \in(0,1), \quad \psi_{a} \equiv \frac{s}{1-\beta q\left(\psi_{u}+\rho_{a}\right)}>0
$$

Given (39), the behavior of inflation under the optimal policy is then determined by $(37)$, and it can be represented by the following linear function of unemployment and productivity:

$$
\pi_{t}=\varphi_{u} \widehat{u}_{t}-\varphi_{a} a_{t}
$$

where

$$
\varphi_{u} \equiv \frac{\alpha_{u}}{\kappa\left(1-\beta(1-x)(1-\delta) \psi_{u}\right)}>0, \quad \varphi_{a} \equiv \frac{\beta(1-\delta)(1-x) \varphi_{u} \psi_{a} \rho_{a}}{\kappa\left(1-\beta(1-x)(1-\delta) \psi_{u}\right)}>0
$$




\section{$6 \quad$ Calibration and Quantitative Analysis}

In order to illustrate the quantitative properties of our model we analyze the responses of inflation and unemployment to a productivity shock implied by the three monetary policy regimes introduced above. We start by discussing our calibration of the model's parameters.

We take each period to correspond to a quarter. For the parameters describing preferences we assume values commonly found in the literature: $\beta=0.99, \phi=1$, $\epsilon=6$ (implying a gross steady state markup $\mathcal{M}=1.2$ ).

We set $\theta=2 / 3$, which implies an average duration of prices of three quarters, which is roughly consistent with the micro and macro evidence on price setting. At this point we do not have any hard evidence on the degree of real wage rigidities, so we set the degree of real wage rigidities, $\gamma$, equal to 0.5 , the midpoint in the admissible range. ${ }^{19}$

In order to calibrate $\alpha$ we exploit a simple mapping between our model and the standard DMP model. In the latter, the expected cost per hire is proportional to the expected duration of a vacancy, which in the steady state is given by $V / H$ where $V$ denotes the number of vacancies. Assuming a matching function of the form $H=Z U^{\eta} V^{1-\eta}$, we have $V / H=Z^{\frac{1}{\eta-1}}(H / U)^{\frac{\eta}{1-\eta}}$. Hence, parameter $\alpha$ in our hiring cost function corresponds to $\eta /(1-\eta)$ in the DMP model. Since estimates of $\eta$ are typically close to $1 / 2$, we assume $\alpha=1$ in our baseline calibration.

Below we analyze two different calibrations for the steady state job finding rate and unemployment rate, which we think of as capturing the characteristics of the US and the European labor markets respectively.

We think of our baseline calibration as capturing the US. We set the job finding rate $x$ equal to 0.7 . This corresponds, approximately, to a monthly rate of 0.3

19. Under an (overly) strict interpretation of our model, $\gamma$ can be obtained through a regression of real wage growth on productivity growth-which is exogenous in our model. Such a regression yields a coefficient between 0.3 and 0.4 , so a value for $\gamma$ between 0.6 and 0.7 . Stepping outside our model, obvious caveats apply, from the measurement of productivity growth, to the direction of causality. 
consistent with U.S. evidence. ${ }^{20}$. In our baseline calibration we set $u$ to 0.05 , which is consistent with the average unemployment rate in the U.S. Given $x$ and $u$ we can determine the separation rate using the relation $\delta=u x /((1-u)(1-x))$. This yields a value for $\delta$ roughly equal to 0.12 .

We choose our alternative calibration to capture the more sclerotic European labor market. Thus we assume $x=0.25$ (which is roughly consistent with a monthly rate of 0.1 ) and $u=0.1$, values in line with evidence for the European Union over the past two decades. The implied separation rate is $\delta=0.04$.

Finally, we need to set a value for $B$, which determines the level of hiring costs. Notice that, in the steady state, hiring costs represent a fraction $\delta g=\delta B x^{\alpha}$ of GDP. Lacking any direct evidence on the latter we choose $B$ so that under our baseline calibration that fraction is one percent of GDP, which seems a plausible upper bound. This implies $B=0.01 /(0.12)(0.7) \simeq 0.11$

Note that the above calibrated parameters, combined with the assumption of an efficient steady state, allow us to pin down $\chi$. Specifically, (8) implies $\chi \simeq 1.03$ under the our baseline/U.S.calibration, and $\chi \simeq 1.22$ under the European one. ${ }^{21}$

\subsection{The Dynamic Effects of Productivity Shocks}

Figures 4 and 5 summarize the effects of a productivity shock under alternative policies. In Figure 4 we assume a purely transitory shock $\left(\rho_{a}=0\right)$, which allows us to isolate the model's intrinsic persistence, whereas in Figure 5 we assume $\rho_{a}=0.9$, a more realistic degree of persistence. In both figures we display the responses for both the U.S. and European labor market calibrations. In all cases we report responses to a one percent decline in productivity, and expressed in percent terms.

20. See Blanchard (2006). We compute the equivalent quarterly rate as $x_{m}+\left(1-x_{m}\right) x_{m}+$ $\left(1-x_{m}\right)^{2} x_{m}$, where $x_{m}$ is the monthly job finding rate.

21. Note that our model can only account for a higher efficient steady state unemployment rate in Europe by assuming a larger disutility of labor. Alternatively, we could have assumed an efficient steady state only for the U.S., and impose the implied $\chi$ to the European calibration as well. In that case, however, the steady state unemployment would not be efficient.and an additional linear term would appear in the loss function, which would render our log-linear approximation to the equilibrium conditions insufficient. 

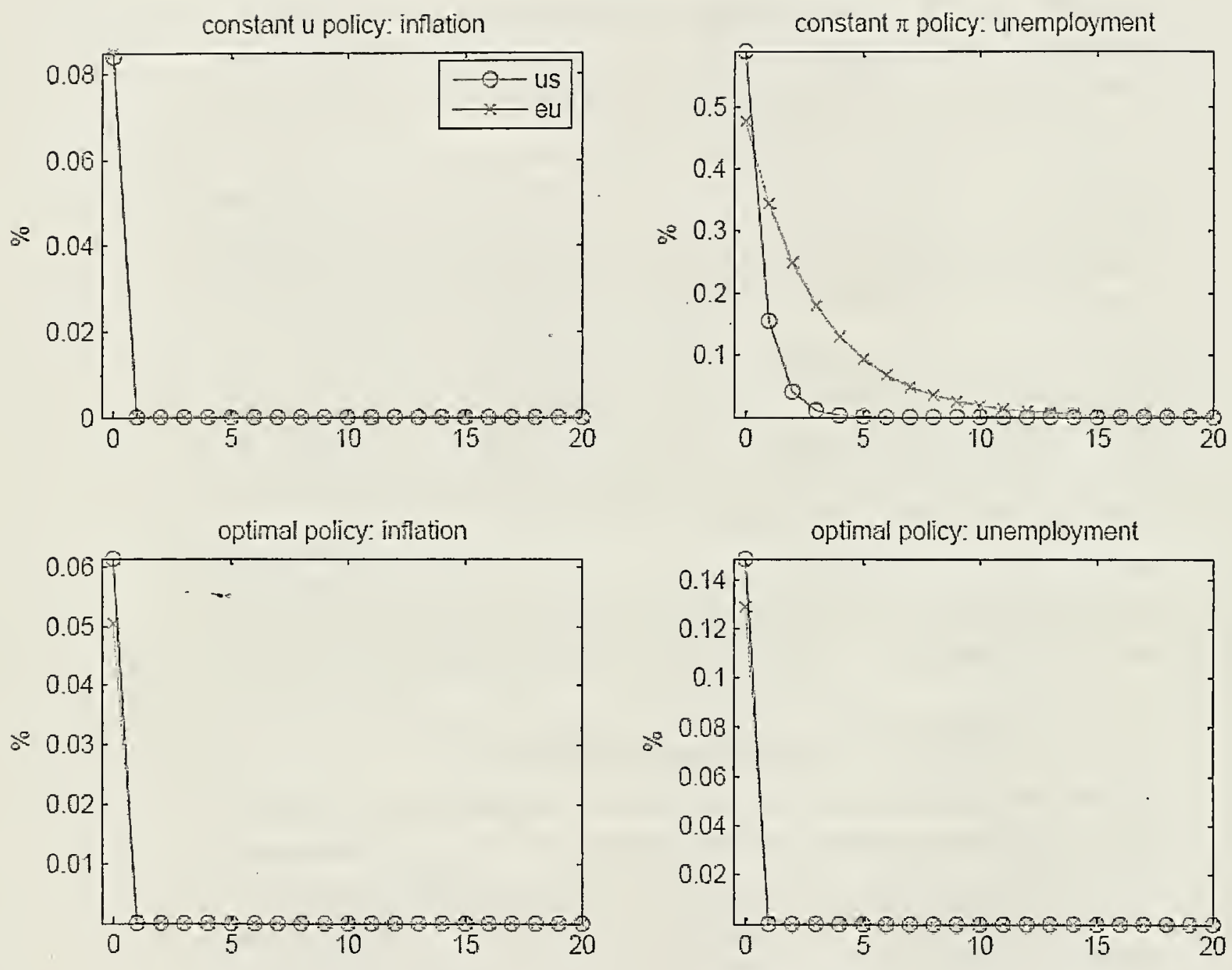

Figure 4. Dynamic Responses to Transitory Productivity Shock 

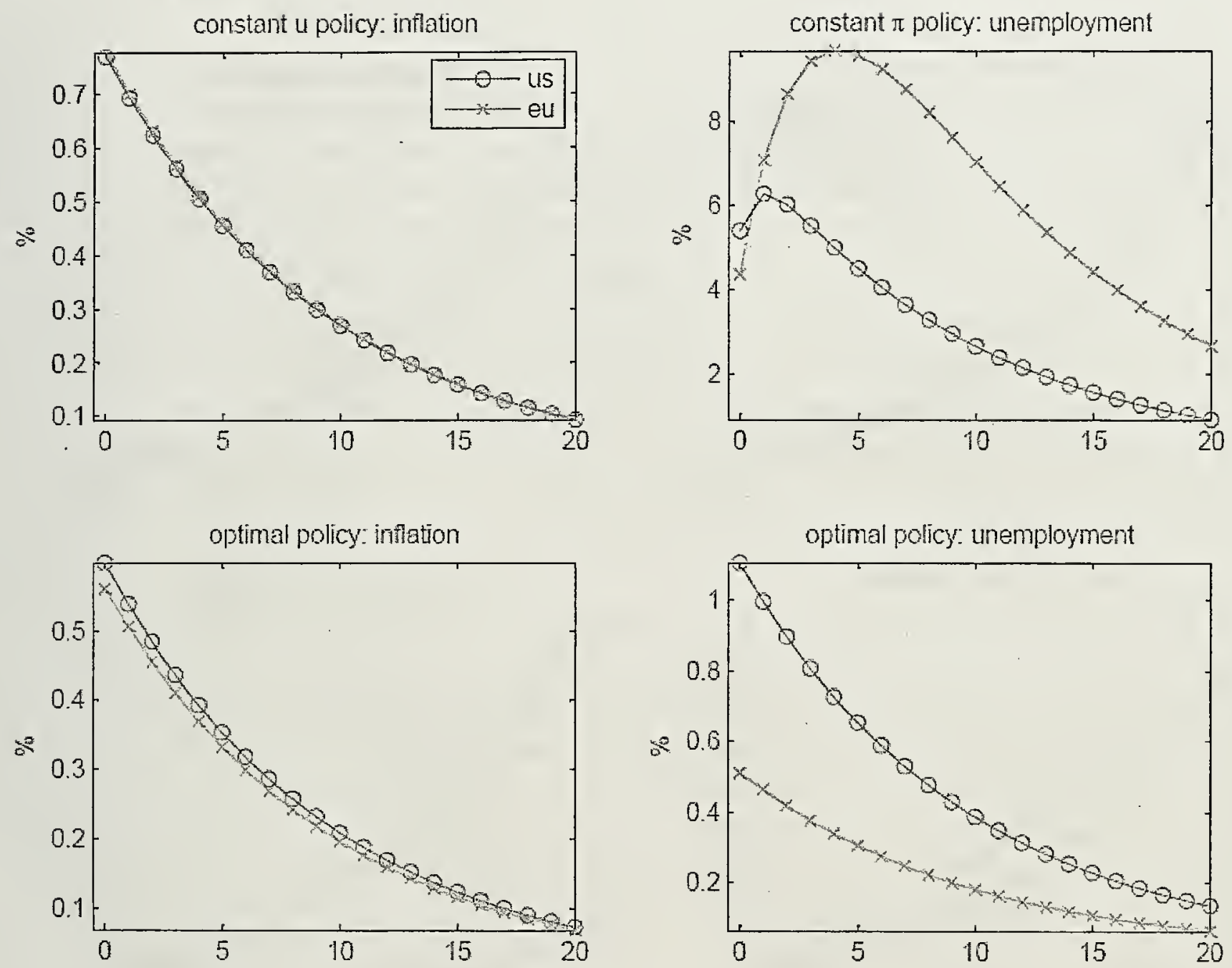

Figure 5. Dynamic Responses to a Persistent Productivity Shock 

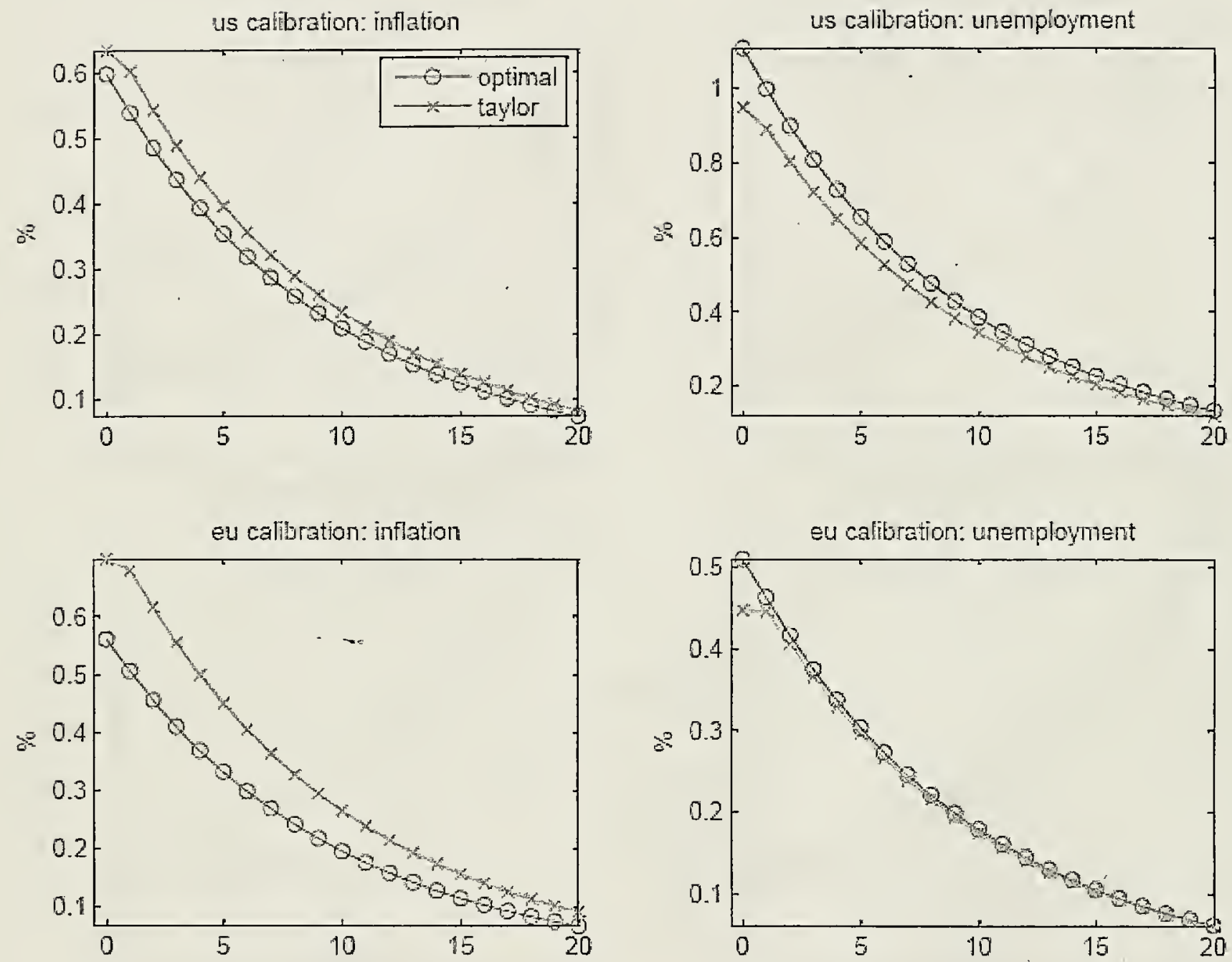

Figure 6. Taylor-type Rule vs. Optimal Policy 
We begin by discussing the case of a transitory shock. As shown in Figure 4, and implied by the analysis above, under a policy that stabilizes unemployment, a transitory shock to productivity has a very limited impact on inflation, which rises less than ten basis points under both calibrations, and displays no persistence. The size of the effect is almost identical for both calibrations.

Under inflation stabilization on the other hand, unemployment rises by about 70 basis points on impact in the U.S. calibration, 60 basis points in the European one. Most interestingly, and as discussed above, unemployment remains above its initial value well after the shock has vanished, with the persistence being significantly greater under the European calibration. The difference in persistence is a consequence of both a lower job finding rate and a smaller separation rate in Europe.

Not surprisingly, the optimal policy strikes a balance between the two, and achieves a highly muted response of both inflation and unemployment. The differences in the responses across the two calibrations is very small, with only a slightly smaller inflation response of inflation in the U.S. calibration being detectable on the graph. Interestingly, the persistence in both variables is negligible (though not zero) under both calibrations. Perhaps the most salient feature of the exercise is the substantial reduction in unemployment volatility under the optimal policy relative to a constant inflation policy, achieved at a small cost in terms of additional inflation volatility.

Figure 5 displays analogous results, under the assumption that $\rho_{a}=0.9$, a more realistic degree of persistence. Now the size of the response of inflation is amplified substantially under the constant unemployment policy, with an increase of more than 70 basis points on impact under both calibrations. This amplification effect reflects the forward looking nature of inflation and the persistent effects on real marginal costs generated by the interaction of the shock and real wage rigidities. Note also that inflation inherits the persistence of the shock.

Given the strong inflationary pressures generated by a persistent adverse productivity shock, it is not surprising that fully stabilizing inflation in the face of those pressures would require large movements in unemployment. This is con- 
firmed by our results, which point to an increase of 6.5 percentage points (!) in the unemployment rate under the U.S. calibration. Interestingly, the unemployment increase under the European calibration is significantly smaller (though still huge): 5.2 percentage points. In both cases unemployment is highly persistent, with its response displaying a prominent hump-shaped pattern. The degree of persistence is remarkably larger under the European calibration, for the same reasons discussed earlier.

Under the optimal policy, the increase in unemployment on impact is about 1 percentage point under the U.S. calibration, half that size under the European one. Note that the size of such responses is several times smaller than under inflation targeting. The price for having a smoother unemployment path is persistently higher inflation, with the latter variable increasing by about 60 basis points under both calibrations.

Interestingly, while the path of inflation implied by the optimal policy is roughly the same under both calibrations, the increase in unemployment is substantially smaller under the European calibration. The explanation for that result has to do with the fact that $\kappa$-the coefficient measuring the sensitivity of inflation to unemployment changes-is smaller under the U.S. calibration, thus implying a larger sacrifice ratio. This is in turn a consequence of a higher separation rate implied by our calibration (0.12 vs. 0.04 )

Why is the Phillips curve flatter in an economy with a high separation rate? The reason is that the sensitivity of marginal cost to changes in the unemployment rate depends on the effects of the latter on the tightness index $x$. As equation (26) makes clear, the higher is the separation rate the smaller is the effect of a given change in unemployment on $x$. This is in turn explained by a lower elasticity of aggregate hirings with respect to unemployment when $\delta$ is high: intuitively, in an economy with high turnover, a change in employment of a given size can be absorbed without much upsetting of the labor market.

Figure 6 illustrates how the optimal responses of inflation and unemployment to a productivity shock can be approximated fairly well by having the central bank 
follow a simple Taylor-type rule of the form

$$
i_{t}=\rho+\phi_{\pi} \pi_{t}-\phi_{u} \widehat{u}_{t}
$$

Casual experimentation with alternative calibrations of the rule suggest that $\phi_{\pi}=1.5$ and $\phi_{u}=0.2$ work fine at approximating the optimal responses under the U.S. calibration. On the other hand, a rule with $\phi_{\pi}=1.5$ and $\phi_{u}=0.6$ does a good job at approximating the optimal responses under the European calibration. Notice that in the latter case the larger coefficient on unemployment is consistent with the smaller required variation in unemployment.

\section{$7 \quad$ Relation to the Literature}

Our model combines four main elements: (1) standard preferences (concave utility of consumption and leisure), (2) labor market frictions, (3) real wage rigidities, (4) price staggering. As a result, it is related to a large and rapidly growing literature.

Merz (1995) and Andolfatto (1996) were the first to integrate (1) and (2), by introducing labor market frictions in an otherwise standard RBC model. In particular, Merz derived the conditions under which Nash bargaining would or would not deliver the constrained-efficient allocation. Both models are richer than ours in allowing for capital accumulation, and in the case of Andolfatto, for both an extensive margin (through hiring) and an intensive margin (through adjustment of hours) for labor. In both cases, the focus was on the dynamic effects of technological shocks, and in both cases, the model was solved through simulations.

Chéron and Langot (2000), Walsh (2003) and Trigari (2006, with a draft circulated in 2003); integrate (1), (2) and (4), by allowing for Calvo nominal price setting by firms. Their models are again much richer than ours. Walsh allows for endogenous separations. Chéron and Langot, as well as Trigari allow for both an extensive and an intensive margin for labor,.with efficient Nash bargaining over hours and the wage. In addition Trigari considers "right to manage" bargaining, 
with the firm choosing freely hours ex-post. Those models are too large to be analytically tractable, and are solved through simulations. The focus of Walsh and Trigari's papers is on the dynamic effects of nominal shocks, while Chéron and Langot study the ability of the model with both technology and monetary shocks to generate a Beveridge curve as well as a Phillips curve. More recent papers, by Walsh (2005), Trigari (2005), Moyen and Sahuc (2005), and Andrés et al. (2006) among others, introduce a number of extensions, from habit persistence in preferences, to capital accumulation, to the implications of Taylor rules. The models in these papers are relatively complex DSGE models, which need to be studied through calibration and simulations.

Shimer (2005) and Hall (2005) were the first to integrate (2) and (3). Shimer argued that, in the standard DMP model, wages were too flexible, and the response of unemployment to technological shocks was too small. Hall (2005) showed first the scope for and then the implications of real wage rigidities in that class of models. These models differ from ours because of their assumption of linear preferences (in addition to their being real models). We have shown earlier the implications. of this difference. But our results, using a standard utility specification, reinforce their conclusion that real wage rigidities are needed to explain fluctuations.

Gertler and Trigari (2005) have explored the implications of integrating (1), (2) and (3). Their model allows for standard preferences, labor market frictions, and real wage staggering a la Calvo. Being a real model, however, it has no room for nominal rigidities. Their model is again too complex to be solved analytically, and is studied through simulations. Their focus is on the dynamic effects of technological shocks.

The paper closest to ours is by Christoffel and Linzert (2005). Like us, it integrates (1) to (4), with standard preferences, labor market frictions, real wage rigidities, and nominal price staggering by firms. Again, their model is substantially more complex than ours, allowing for both extensive and intensive margins for labor, and either efficient Nash bargaining, or right to manage. The model is solved through simulations. The main focus is on inflation persistence in response to monetary policy shocks. 
This brief (and surely partial) review makes clear that we cannot fully claim originality of purpose. Our aim was to develop and present a structure simple enough that its solution can be characterized analytically, the dynamic effects of shocks can be related to the underlying parameters, and optimal policy can be derived. In contrast, much of the related literature described above falls short of any normative analysis, due to the complexity of the models involved. We think that our analytical model is a needed step in the development of these more complex models.

\section{Conclusions}

We have constructed a model with labor market frictions, real wage rigidities, and staggered price setting. The model thus integrates the key elements of the New Keynesian framework and the Diamond-Mortensen-Pisarrides search model of labor market flows. -

The three ingredients above are all needed if one is to explain movements in unemployment, the effects of changes in productivity on the economy, and the role of monetary policy in shaping those effects.

We have derived the constrained-efficient allocation, and the equilibrium in the decentralized economy in the presence of real wage rigidities and sticky prices. The optimal monetary policy has been shown to minimize a weighted average of unemployment and inflation fluctuations.

The extent of real wage rigidities determines the amplitude of unemployment fluctuations under the optimal policy. Furthermore, unemployment displays intrinsic persistence, i.e. persistence beyond that inherited from productivity. The degree of persistence is decreasing in the job finding rate. Hence, the more sclerotic is the labor market the more persistence is unemployment.

In the presence of real wage rigidities, strict inflation targeting does not deliver the best monetary policy. As in Blanchard and Gali (2005), the reason is that distortions vary with shocks. The best policy implies some accommodation of inflation, and comes with some persistent fluctuations in unemployment. 


\section{Appendix A: Derivation of the New Keynesian Phillips Curve with Hiring Costs}

\section{The Optimal Price Setting Problem}

Let $X_{t+k \mid t}$ denote the value of a variable $X$ in period $t+k$ for a firm that last reset its price in period $t . P_{t}^{*}$ denotes the price set by this firm at time $t . Q_{t, t+k} \equiv$

$\beta^{k} \frac{C_{t}}{C_{t+k}} \frac{P_{t}}{P_{t+k}}$ is now the stochastic discount factor for nominal payoffs. A firm resetting prices in period $t$ maximizes its value, given by

$$
\begin{aligned}
V_{t}\left(N_{t-1 \mid t}\right)= & \max _{P_{t}^{*}} E_{t} \sum_{k=0}^{\infty} \theta^{k} Q_{t, t+k}\left[P_{t}^{*} Y_{t+k \mid t}-P_{t+k}\left(W_{t+k} N_{t+k \mid t}+G_{t+k} H_{t+k \mid t}\right)\right] \\
& +(1-\theta) E_{t} \sum_{k=0}^{\infty} \theta^{k} Q_{t, t+k+1} V_{t+k+1}\left(N_{t+k \mid t}\right)
\end{aligned}
$$

subject to

$$
\begin{gathered}
Y_{t+k \mid t}=A_{t+k} N_{t+k \mid k} \\
Y_{t+k \mid t}=\left(\frac{P_{t}^{*}}{P_{t+k}}\right)^{-\epsilon}\left(C_{t+k}+G_{t+k} H_{t+k}\right)
\end{gathered}
$$

where $H_{t+k \mid t}=N_{t+k \mid t}-(1-\delta) N_{t+k-1 \mid t}$ and $P_{t} \equiv\left(\int_{0}^{1} P_{t}(j)^{1-\epsilon} d j\right)^{\frac{1}{1-\epsilon}}$ is the aggregate price index.

Notice that, in contrast with the Calvo model without hiring costs, the payoffs associated with the current price decision now include a term corresponding to the period after the end of the life of the newly set price. That term takes the form of a weighted average of the value of the firm at the time or resetting the price, with the weights, $(1-\theta) \theta^{k}$, corresponding to the probability that this happens at each possible horizon. The reason is that $P_{t}^{*}$ will still have some influence on the payoff's of that period through its effect on inherited employment and, hence, on hiring requirements.

Even though the profits of a firm resetting its price at time $t$ will be be influenced by its lagged employment, the price decision will be independent of past variables. That result, which allows our model to preserve all the aggregation properties of 
the basic Calvo framework, follows from our assumption of linear hiring costs at the firm level.

Differentiating objective function (40) with respect to $P_{t}^{*}$ and using constraints (41) and (42), as well as the envelope property $V_{t}^{\prime}\left(N_{t-1 \mid t}\right)=(1-\delta) P_{t} G_{t}$ (which must hold for all $t$ ) we obtain the optimality condition

$$
\begin{aligned}
0= & E_{t} \sum_{k=0}^{\infty} \theta^{k} Q_{t, t+k}\left[Y_{t+k \mid t}(1-\epsilon)+\epsilon \frac{P_{t+k} W_{t+k}}{P_{t}^{*}} N_{t+k \mid t}-P_{t+k} G_{t+k} \frac{d H_{t+k \mid t}}{d P_{t}^{*}}\right] \\
& -\epsilon(1-\delta)(1-\theta) E_{t} \sum_{k=0}^{\infty} \theta^{k} Q_{t, t+k+1} \frac{P_{t+k+1} G_{t++k+1}}{P_{t}^{*}} N_{t+k \mid t}
\end{aligned}
$$

where

$$
\begin{aligned}
\frac{d H_{t+k \mid t}}{d P_{t}^{*}} & =\frac{1}{A_{t+k}} \frac{d Y_{t+k \mid t}}{d P_{t}^{*}}-(1-\delta) \frac{1}{A_{t+k-1}} \frac{d Y_{t+k-1 \mid t}}{d P_{t}^{*}} \\
& =-\frac{\epsilon}{P_{t}^{*}}\left[N_{t+k \mid t}-(1-\delta), N_{t+k-1 \mid t}\right] \cdots
\end{aligned}
$$

for $k=1,2,3,$. and $\frac{d H_{t \mid t}}{d P_{t}^{t}}=-\frac{\epsilon}{P_{t}^{*}} N_{t \mid t}$ for $k=0$.

Collecting terms and letting $\mathcal{M} \equiv \frac{\epsilon}{\epsilon-1}$ denote the gross desired markup we have

$$
\begin{aligned}
0= & E_{t} \sum_{k=0}^{\infty} \theta^{k} Q_{t, t+k}\left[Y_{t+k \mid t}\right. \\
& \left.-\mathcal{M} \frac{P_{t+k}}{P_{t}^{*}}\left(W_{t+k}+G_{t+k}-(1-\delta) Q_{t+k, t+k+1} \frac{P_{t+k+1}}{P_{t+k}} G_{t+k+1}\right) N_{t+k i t}\right]
\end{aligned}
$$

which can be seen to be independent of $N_{t-1 \mid t}$, thus implying that all firms resetting their price in period $t$ will choose the same price $P_{t}^{*}$, independently of their price history (and, hence, their employment in the previous period). This is a consequence of our assumption of hiring costs which are linear in the firm's hiring level, thus implying that lagged employment does not affect marginal cost or marginal revenue (even though it will influence the level of profits). In turn, that property allows us to preserve the aggregation properties of the basic Calvo model. 
Rearranging terms we have

$$
0=E_{t} \sum_{k=0}^{\infty} \theta^{k} Q_{t, t+k} Y_{t+k \mid t}\left(P_{t}^{*}-\mathcal{M} P_{t+k} M C_{t+k}\right)
$$

where

$$
M C_{t} \equiv \frac{W_{t}}{A_{t}}+g\left(x_{t}\right)-\beta(1-\delta) E_{t}\left\{\frac{u^{\prime}\left(C_{t+1}\right)}{u^{\prime}\left(C_{t}\right)} \frac{A_{t+1}}{A_{t}} g\left(x_{t+1}\right)\right\}
$$




\section{Appendix B: Derivation of the Welfare Loss Function}

Under our assumed utility specification we have:

$$
u\left(C_{t}\right)=\log C_{t}=c+\widehat{c}_{t}
$$

and

$$
\begin{aligned}
v\left(N_{t}\right) & =\chi \frac{N_{t}^{1+\phi}}{1+\phi} \\
& \simeq \chi \frac{N^{1+\phi}}{1+\phi}+\chi N^{1+\phi}\left(\frac{N_{t}-N}{N}\right)+\frac{1}{2} \phi \chi N^{1+\phi}\left(\frac{N_{t}-N}{N}\right)^{2} \\
& \simeq \chi \frac{N^{1+\phi}}{1+\phi}+\chi N^{1+\phi} \widehat{n}_{t}+\frac{1}{2}(1+\phi) \chi N^{1+\phi} \widehat{n}_{t}^{2}
\end{aligned}
$$

where we have made use of the fact that up to second order $\frac{N_{t}-N}{N} \simeq \widehat{n}_{t}+\frac{1}{2} \widehat{n}_{t}^{2}$. Hence, the deviation of period utility from its steady state value, denoted by $U_{t}$, is given by

$$
U_{t} \simeq \widehat{c}_{t}-\chi N^{1+\phi} \widehat{n}_{t}+\frac{1}{2}(1+\phi) \chi N^{1+\phi} \widehat{n}_{t}^{2}
$$

Next we derive an equation that relates, up to a second order approximation, $\widehat{c}_{t}$ and $\widehat{n}_{t}$..Market clearing for good $i$ requires that $A_{t}\left(N_{t}(i)-g\left(x_{t}\right) H_{t}(i)\right)=C_{t}(i)$. Integrating over $i$ yields:

$$
\begin{aligned}
A_{t}\left(N_{t}-g\left(x_{t}\right) H_{t}\right) & =\int_{0}^{1} C_{t}(i) d i \\
& =C_{t} \int_{0}^{1} \frac{C_{t}(i)}{C_{t}} d i \\
& =C_{t} \int_{0}^{1}\left(\frac{P_{t}(i)}{P_{t}}\right)^{-\epsilon} d i \\
& \equiv C_{t} D_{t}
\end{aligned}
$$

where $D_{t} \equiv \int_{0}^{1}\left(\frac{P_{t}(i)}{P_{t}}\right)^{-\epsilon} d i$

Thus we can write

$$
\frac{C_{t} D_{t}}{A_{t} N_{t}}-1=-g\left(x_{t}\right) \frac{H_{t}}{N_{t}}
$$


Notice that the right-hand side term equals $-\delta g$ in the steady state. Hence, under our assumption on the order of magnitude of $\delta$ and $g$, it is already of second order relative to employment fluctuations. Thus it suffices to derive a first-order Taylor expansion:

$$
\begin{aligned}
g\left(x_{t}\right) \frac{H_{t}}{N_{t}} & \simeq \delta g+\alpha g \delta \widehat{x}_{t}+g(1-\delta) \widehat{n}_{t}-g(1-\delta) \widehat{n}_{t-1} \\
& \simeq \delta g+g(1-\delta+\alpha) \widehat{n}_{t}-g(1-\delta)(1+\alpha(1-x)) \widehat{n}_{t-1}
\end{aligned}
$$

where we have made use of equation (26) as well as the fact that $g^{\prime} x=\alpha g$.

Hence we have

$$
\frac{C_{t} D_{t}}{A_{t} N_{t}(1-\delta g)} \simeq 1-\frac{g(1-\delta+\alpha)}{1-\delta g} \widehat{n}_{t}+\frac{g(1-\delta)(1+\alpha(1-x))}{1-\delta g} \widehat{n}_{t-1}
$$

Taking logs on both sides, and realizing that the terms in $\widehat{n}_{t}$ and $\widehat{n}_{t-1}$ are premultiplied by $g$ and hence are already of second order:

$$
\widehat{c}_{t}=a_{t}-d_{t}+\frac{1-g(1+\alpha)}{1-\delta g} \widehat{n}_{t}+\frac{g(1-\delta)(1+\alpha(1-x))}{1-\delta g} \widehat{n}_{t-1}
$$

Lemma: up to a second order approximation, $d_{t} \equiv \log D_{t} \simeq \frac{\epsilon}{2} \operatorname{var}_{i}\left(p_{t}(i)\right)$.

Proof: see appendix C.

Using (43) and (44), we can write the expected discounted sum of period utilities. as follows:

$$
\begin{aligned}
E_{0} \sum_{t=0}^{\infty} \beta^{t} U_{t} \simeq & \frac{\epsilon}{2} E_{0} \sum_{t=0}^{\infty} \beta^{t} \operatorname{var}_{i}\left(p_{t}(i)\right)-\frac{1}{2}(1+\phi) \chi N^{1+\phi} E_{0} \sum_{t=0}^{\infty} \beta^{t} \widehat{n}_{t}^{2} \\
& +E_{0} \sum_{t=0}^{\infty} \beta^{t}\left(\frac{1-g(1+\alpha)+\beta(1-\delta) g(1+\alpha(1-x))}{1-\delta g}-\chi N^{1+\phi}\right) \widehat{n}_{t} \\
& + \text { t.i.p. }
\end{aligned}
$$

Assuming that the economy fluctuates around the efficient steady state, we can 
use (8) to show that the coefficient on $\widehat{n}_{t}$ equals zero.

The following result allows us to express the cross-sectional variance of prices as a function of inflation:

Lemma: $\sum_{t=0}^{\infty} \beta^{t} \operatorname{var}_{i}\left(p_{t}(i)\right)=\frac{1}{\lambda} \sum_{t=0}^{\infty} \beta^{t} \pi_{t}^{2}$

Proof: Woodford (2003)

Combining the previous results, together with our definition of the unemployment rate $u_{t}$, we can write the welfare losses from fluctuations around the efficient steady state (ignoring terms independent of policy or lagged as

$$
\begin{aligned}
L & \equiv \frac{1}{2} E_{0} \sum_{t=0}^{\infty} \beta^{t}\left[\frac{\epsilon}{\lambda} \pi_{t}^{2}+(1+\phi) \chi\left(1-u^{*}\right)^{\phi-1} \widehat{u}_{t}^{2}\right] \\
& =\frac{1}{2} \frac{\epsilon}{\lambda} E_{0} \sum_{t=0}^{\infty} \beta^{t}\left(\pi_{t}^{2}+\alpha_{u} \widehat{u}_{t}^{2}\right)
\end{aligned}
$$

where $\alpha_{u} \equiv\left(\lambda(1+\phi) \chi\left(1-u^{*}\right)^{\phi-1}\right) / \epsilon>0$. 


\section{Appendix C}

From the definition of the price index, in a neighborhood of the zero inflation steady state:

$$
\begin{aligned}
1 & =\int_{0}^{1}\left(\frac{P_{t}(i)}{P_{t}}\right)^{1-\epsilon} d i \\
& =\int_{0}^{1} \exp \left\{(1-\epsilon)\left(p_{t}(i)-p_{t}\right)\right\} d i \\
& \simeq 1+(1-\epsilon) \int_{0}^{1}\left(p_{t}(i)-p_{t}\right) d i+\frac{(1-\epsilon)^{2}}{2} \int_{0}^{1}\left(p_{t}(i)-p_{t}\right)^{2} d i
\end{aligned}
$$

thus implying

$$
p_{t} \simeq \int_{0}^{1} p_{t}(i) d i+\frac{(1-\epsilon)}{2} \int_{0}^{1}\left(p_{t}(i)-p_{t}\right)^{2} d i
$$

By definition,

$$
\begin{aligned}
D_{t} & \equiv \int_{0}^{1}\left(\frac{P_{t}(i)}{P_{t}}\right)^{-\epsilon} d i \\
& =\int_{0}^{1} \exp \left\{-\epsilon\left(p_{t}(i)-p_{t}\right)\right\} d i \\
& \simeq 1-\epsilon \int_{0}^{1}\left(p_{t}(i)-p_{t}\right) d i+\frac{\epsilon^{2}}{2} \int_{0}^{1}\left(p_{t}(i)-p_{t}\right)^{2} d i \\
& \simeq 1+\frac{\epsilon(1-\epsilon)}{2} \int_{0}^{1}\left(p_{t}(i)-p_{t}\right)^{2} d i+\frac{\epsilon^{2}}{2} \int_{0}^{1}\left(p_{t}(i)-p_{t}\right)^{2} d i \\
& =1+\frac{\epsilon}{2} \int_{0}^{1}\left(p_{t}(i)-p_{t}\right)^{2} d i
\end{aligned}
$$

It follows that $d_{t} \simeq(\epsilon / 2) \operatorname{var}_{i}\left(p_{t}(i)\right)$ up to a second order approximation. 


\section{References}

Andolfatto, David (1996): "Business Cycles and Labor Market Search," American Economic Review, 86-1, 112-132

Andrés, Javier, Rafael Domenech, and Javier Ferri (2006): "Price Rigidity and the Volatility of Vacancies and Unemployment," mimeo, Universidad de Valencia.

Barro, Robert (1988): "The Persistence of Unemployment," American Economic Review, vol. 78-2, May, 32-37.

Blanchard, Olivier J., and Jordi Gali (2006): "Real Wage Rigidities and the New Keynesian Model," Journal of Money Credit and Banking, forthcoming.

Chéron, Arnaud, and François Langot (2000): "The Phillips and Beveridge Curves Revisited," Economics Letters 69, 371-376.

Christoffel, Kai, and Tobias Linzert (2005): "The Role of Real Wage Rigidities and Labor Market Frictions for Unemployment and Inflation Dynamics", Discussion Paper 556, European Central Bank

Galí, Jordi and Mark Gertler (1999): "Inflation Dynamics: A Structural Econometric Analysis," Journal of Monetary Economics, vol. 44, nº 2, 195-222, 1999

Gertler, Mark, and Antonella Trigari (2005), "Unemployment Fluctuations with Staggered Nash Wage Bargaining," mimeo, November.

Hall, Robert (2005): "Employment Fluctuations with Equilibrium Wage Stickiness," American Economic Review vol. 95, no. 1, 50-64.

Krause, Michael, Thomas Lubik (2005): "The (Ir)relevance of Real Wage rigidities in the New Keynesian Model with Search Frictions," mimeo.

Merz, Monica (1995), "Search in the Labor Market and the Real Business Cycle", Journal of Monetary Economics, 36, 269-300

Moyen, Stephane, and Jean Guillaume Sahuc (2005), "Incorporating labour market frictions into an optimizing-based monetary policy model", Economic Modelling 22, 159-186

Pissarides, Christopher (2000): Equilibrium Unemployment Theory, MIT Press. 
Rotemberg, Julio and Michael Woodford (1999): "The Cyclical Behavor of Prices and Costs," in Handbook of Macroeconomics, J. Taylor and M. Woodford eds., Elsevier-North Holland.

Shimer, Robert (2005): "The Cyclical Behavior of Equilibrium unemployment and Vacancies," American Economic Review vol. 95, no. 1, 25-49.

Summers, Lawrence (1991): "The Scientific Illusion in Empirical Macroeconomics," Scandinavian Journal of Economics vol. 93, no. 2, 129-148.

Trigari, Antonella (2005): "Equilibrium Unemployment, Jab flows, and Inflation Dynamics," ECB WP\#304.

Trigari, Antonella (2006): "The Role of Search Frictions and Bargaining of Inflation Dynamics", mimeo.

Walsh, Carl (2003): "Labor Market Search and Monetary Shocks", in Elements of Dynamic Macroeconomic Analysis, S. Altug, J. Chadha and C. Nolan eds.

Walsh, Carl (2005): "Labor market search, Sticky Prices, and Interest Rate Rules", Review of Economic Dynamics, 8, 829-849 



